\title{
Forward Conduction Mode Controlled Piezoelectric Transformer-Based PFC LED Drive
}

\author{
Roedgaard, M. S.; Weirich, M.; Andersen, M. A. E.
}

Published in:

I E E E Transactions on Power Electronics

Link to article, DOI:

10.1109/TPEL.2012.2233499

Publication date:

2013

Document Version

Publisher's PDF, also known as Version of record

Link back to DTU Orbit

Citation (APA):

Roedgaard, M. S., Weirich, M., \& Andersen, M. A. E. (2013). Forward Conduction Mode Controlled Piezoelectric Transformer-Based PFC LED Drive. I E E E Transactions on Power Electronics, 28(10), 4841-4849.

https://doi.org/10.1109/TPEL.2012.2233499

\section{General rights}

Copyright and moral rights for the publications made accessible in the public portal are retained by the authors and/or other copyright owners and it is a condition of accessing publications that users recognise and abide by the legal requirements associated with these rights.

- Users may download and print one copy of any publication from the public portal for the purpose of private study or research.

- You may not further distribute the material or use it for any profit-making activity or commercial gain

- You may freely distribute the URL identifying the publication in the public portal 


\title{
Forward Conduction Mode Controlled Piezoelectric Transformer-Based PFC LED Drive
}

\author{
Martin S. Rødgaard, Michael Weirich, Member, IEEE, and Michael A. E. Andersen, Member, IEEE
}

\begin{abstract}
Light-emitting diode (LED) illumination is getting more and more common; as LED's performance is rising, the price is falling and is getting competitive. Some of the challenges of ac mains supplied illumination are the requirement of power factor correction (PFC) and the competitiveness of a low priced market. In this paper, a new forward conduction mode (FCM) control method for piezoelectric transformer (PT)-based power converters is proposed. A PT-based LED drive facilitating passive PFC is developed, utilizing and validating the FCM control method. The drive utilizes an inductorless half-bridge topology and for circuit minimization and simplicity it has no load regulation and has a $100-\mathrm{Hz}$ output modulation. The proposed FCM control method ensures that the PT is operated at its optimal operation frequency, which ensures soft-switching operation and a constant gain. As a result a $6.5-\mathrm{W}$ PT-based PFC LED drive has been developed, supplied from 230-V $50-\mathrm{Hz}$ ac mains, achieving a power factor of 0.96 .
\end{abstract}

Index Terms-Forward conduction mode (FCD) control, lightemitting diode (LED), power factor correction (PFC), piezoelectric transformer (PT).

\section{INTRODUCTION}

$\mathbf{F}$ OR low-power applications, such as light-emitting diode (LED) illumination [1], [2], the piezoelectric transformer (PT) offers minimization of component count and overall size [3]-[7], as well as potential high efficiency [4]-[7] and low production cost. The market of ac mains supplied illumination is very competitive, demanding low product prices and making it challenging to enter the market. But as LED's performance is rising and the price is falling, LED illumination is getting more and more popular as an more environmentally friendly alternative to traditional illumination [2], [8]-[13]. One of the challenges of ac mains supplied illumination is the EN610003-2 requirement of power factor correction (PFC).

In this paper, a new forward conduction mode (FCM) control method for PT-based power converters is proposed, as well as a PT-based LED drive facilitating passive PFC is developed. Fig. 1 illustrates a functional block diagram of the proposed PT

Manuscript received August 8, 2012; revised October 18, 2012; accepted November 28, 2012. Date of current version March 15, 2013. This work was supported by the Danish National Advanced Technology Foundation under Grant HTF-008-2008-3 and the Advanced Technology Foundation. Recommended for publication by Associate Editor J. M. Alonso.

M. S. Rødgaard and M. A. E. Andersen are with the Department of Electrical Engineering, Technical University of Denmark, Kongens, Lyngby DK-2800, Denmark (e-mail: msr@elektro.dtu.dk; ma@elektro.dtu.dk).

M. Weirich is with the Fairchild Semiconductor GmbH, D-82256 Fuerstenfeldbruck, Germany (e-mail: michael.weirich@ fairchildsemi.com).

Color versions of one or more of the figures in this paper are available online at http://ieeexplore.ieee.org.

Digital Object Identifier 10.1109/TPEL.2012.2233499

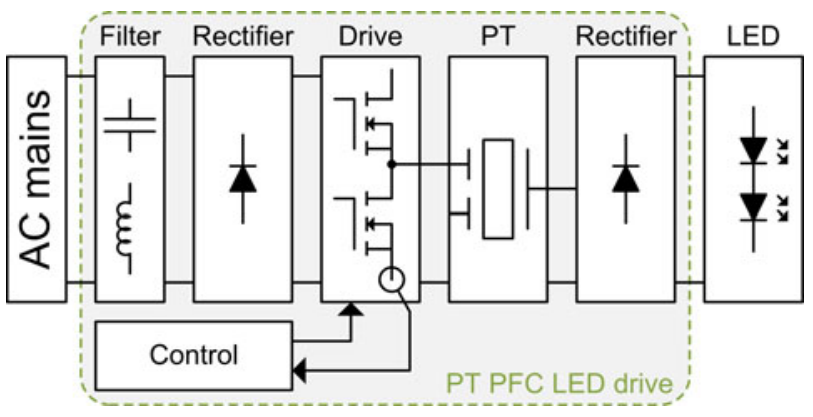

Fig. 1. Functional block diagram of the PT LED drive, employing passive PFC and the forward conduction mode (FCM) control.

LED drive, which consist of an input filter, a full-bridge rectifier, an inductorless half-bridge drive, with FCM control, and the PT, followed by an output rectifier and the LED load.

In order to achieve consistent and efficient operation, the inductorless half-bridge topology requires a zero voltage switching (ZVS) optimized PT [3], [14]-[16]. This application utilizes a 20-mm radial mode ZVS optimized PT [7], [17]-[19]. Usually, a series inductor is necessary, in order to achieve ZVS operation and avoid large hard switching losses. But with the elimination of a bulky series inductor, the size and cost of the driver are minimized.

The operation frequency is one of the most critical parts, when utilizing PT-based converters, as the PT resonance frequency is very narrow [3], [5]-[7], [14]-[16], [20]-[22]. Some of the most common control methods are phase lock loop (PLL) [23]-[27] and resonance current control [28], but self-tuned control has also been proposed [29]. In this study, a new FCM control method is proposed and relies on a detection of the forward conduction period of the half-bridge switches, which reflects the resonance current phase lag. The control method is fairly simple and ensures a controlled and optimal operation frequency, which ensures soft-switching operation and a constant gain.

$\mathrm{PFC}$ can be obtained in various ways and for higher power and high-quality converters, this is typically obtained in the first of two stages, but for low-power and low-price converters only a single stage is feasible. In PT-based converters, several single-stage charge-pump topologies offer PFC [28], [30]-[33], but have demanding requirements for the PT. In this approach, PFC is obtained simply by having a sufficiently small input buffer capacitor, allowing the half-bridge supply voltage to be modulated by the $100-\mathrm{Hz}$ rectified ac mains voltage. As a result, the output power has $100-\mathrm{Hz}$ modulation as well; however, this is acceptable for this LED application. Furthermore, this design has no load regulation, as the LED resembles a fairly constant 


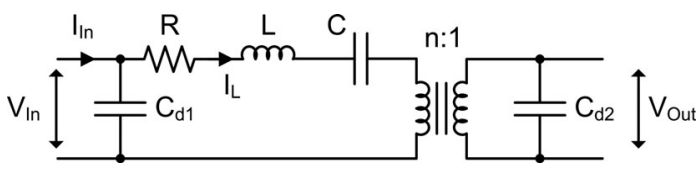

Fig. 2. Lumped parameter model, which describes the behavior of the PT in a narrow band around the operating resonance mode [35].

TABLE I

LumPed PARAMETER MODEl PARAMETERS OF THE UTILIZED 20-MM RADIAL MODE PT

\begin{tabular}{|c|c|c|c|c|c|}
\hline $\mathrm{R}$ & $\mathrm{L}$ & $\mathrm{C}$ & $\mathrm{C}_{\mathrm{d} 1}$ & $\mathrm{C}_{\mathrm{d} 2}$ & $\mathrm{n}$ \\
\hline $12.4 \Omega$ & $9.46 \mathrm{mH}$ & $219 \mathrm{pF}$ & $1.19 \mathrm{nF}$ & $131 \mathrm{nF}$ & 8.15 \\
\hline
\end{tabular}

load and the implementation of load regulation will just increase complexity and price.

In the following section, a basic introduction to PTs is given. Section II describes the utilized inductorless half-bridge topology, its operation, and how passive PFC is obtained. Section III presents and explains the proposed FCM control. And finally, Section IV presents a developed prototype PT LED drive, which is verified through experimental results, followed by a conclusion in Section V.

\section{A. Piezoelectric Transformer}

PTs are based on piezoelectric ceramic materials, which have an electromechanical coupling. A PT is basically two piezoelectric elements joined together to form a transformer. The primary-side element is then excited by an electrical ac voltage, which induces a deformation of the joined PT structure. The deformation of the secondary-side element generates an output voltage and through a proper PT design, a desired primary to secondary voltage conversion can be obtained. In order to convert energy at a high efficiency, the PT is operated in one of its resonance modes [6], [7], [34]. The PT resonates each time it is possible to generate a standing sound wave in the structure. But in order to obtain the highest efficiency, the PT design is usually optimized for one specific resonance mode [6], [7], [34].

The electromechanical structure resembles a distributed network, but for simplicity and mathematical representation, normally only the resonance mode of interest is modeled [6], [7]. One of the most used PT models is the lumped parameter model [6], [7], [21], [22], [35], which is illustrated in Fig. 2. The model is basically an electrical $L C C$ resonance tank and the behavior of a PT-based converter is also quite similar to a traditional resonance converter.

The PT used for this application is a 20 -mm radial mode PT [7], [17]-[19] and its primary resonance frequency is approximately $114 \mathrm{kHz}$. The PT is not designed for this particular application, which results in a degradation in efficiency. The PT has the model parameters of Table I and is not treated in further detail in this paper.

\section{INDUCTORLESS HALF-BRIDGE TOPOLOGY}

The proposed PT LED drive utilizes an inductorless halfbridge topology [3], [14]-[16], [22], [26], which eliminates the

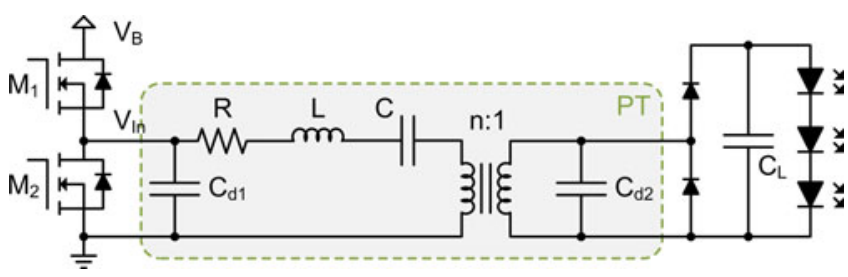

Fig. 3. Schematic diagram of the inductorless half-bridge topology.

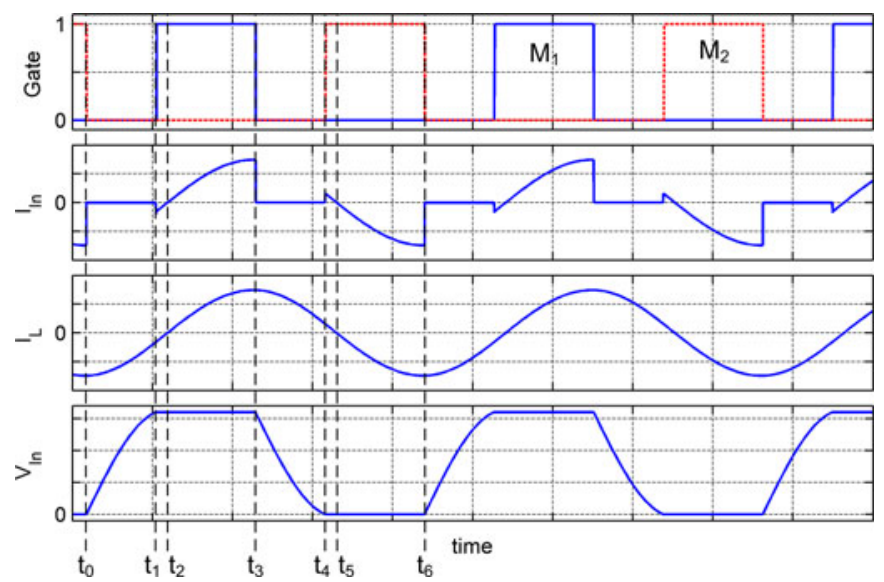

Fig. 4. Operational waveforms of the inductorless half-bridge topology.

bulky series inductor and only converts energy through the electromechanical PT resonance tank. Fig. 3 illustrates the inductorless half-bridge, consisting of a MOSFET-based half-bridge, the lumped parameter model a half-bridge output rectifier, and an output voltage buffer capacitor, followed by the LED load. Usually, a series inductor is required in the PT-based half-bridge topology [5], [29], in order to achieve ZVS operation of the half-bridge switches and avoid large hard switching losses, in connection to the PT input capacitor $C_{d 1}$. But through a ZVS optimized PT design, soft switching can be obtained without auxiliary components [3], [14]-[16], [19]. However, the ZVS operation of a ZVS optimized PT is only obtainable in a narrow frequency band, located just above the operating resonance frequency, where the series resonance ( $L$ and $C$ of the lumped parameter model) becomes inductive and possesses enough resonating energy to charge and discharge $C_{d 1}$. Hence, the excitation frequency is key, in order to achieve ZVS, consistent and efficient operation.

\section{A. Operational Principle}

Fig. 4 illustrates the steady-state operation of the inductorless half-bridge PT topology, which is operated slightly above its resonance frequency, where inductivity and resonating energy are maximized. The circuit (see Fig. 3) has six modes of operation, divided into the following periods.

$t_{0}-t_{1}$ : both switches are turned OFF in this period the reverse resonance current $I_{L}$ charges the input capacitor $C_{d 1}$.

$t_{1}-t_{2}$ : when the input capacitor $C_{d 1}$ is charged to the supply voltage, the body diode of $M_{1}$ conducts the reverse resonance current $I_{L}$ and in this period $M_{1}$ is switched ON, achieving ZVS. 
$t_{2}-t_{3}$ : at $t_{2}$ the resonance current $I_{L}$ is inverted, and switch $M_{1}$ conducts the resonance current $I_{L}$ and transfers energy to the resonance tank.

$t_{3}-t_{4}$ : at $t_{3}$ switch $M_{1}$ is turned OFF and the resonance current $I_{L}$ discharges the input capacitor $C_{d 1}$.

$t_{4}-t_{5}$ : when the input capacitor $C_{d 1}$ is totally discharged, the body diode of $M_{2}$ conducts the resonance current $I_{L}$ and in this period $M_{2}$ is switched $\mathrm{ON}$, achieving ZVS.

$t_{5}-t_{6}$ : at $t_{5}$ the resonance current $I_{L}$ is reversed and the resonance current $I_{L}$ is freewheeling through switch $M_{2}$. The period ends at $t_{6}$, where $M_{2}$ is switched OFF and a new cycle begins.

As mentioned, the switches should be turned $\mathrm{ON}$ in between the time periods $t_{1}-t_{2}$ and $t_{4}-t_{5}$, so sufficient dead time should be supplied to the gate signals, in order to utilize the ZVS capability.

\section{B. Power Factor Correction}

The PT LED drive utilizes passive PFC, which is achieved by having a sufficiently small supply voltage buffer capacitor $C_{B}$, after the input full-bridge rectifier. In this way, the half-bridge supply voltage $V_{B}$ will follow the rectified ac mains voltage and the resonance current will be proportional to the excitation voltage, as shown in (2) (assuming a consistent operation point and load). The transfer function (1) describes the voltage conversion of the lumped parameter model (see Fig. 2) and (2) describes the resonance current, where an ac input voltage $V_{\text {In }}$ is applied, $Z_{\text {In }}$ is the PT input impedance (excluding $C_{d 1}$ ), and $R_{L}$ is the load resistance

$$
\begin{aligned}
\frac{V_{\text {Out }}}{V_{\text {In }}} & =\frac{\frac{1}{j \omega C_{d 2}} \| R_{L}}{\left(R+j \omega L+\frac{1}{j \omega C}\right) / n^{2}+\left(\frac{1}{j \omega C_{d 2}} \| R_{L}\right)} \frac{1}{n} \\
I_{L} & =\frac{V_{\text {In }}}{Z_{\text {In }}}=\frac{V_{\text {In }}}{R+j \omega L+\frac{1}{j \omega C}+\left(\frac{1}{j \omega C_{d 2}} \| R_{L}\right) n^{2}} .
\end{aligned}
$$

Fig. 5 illustrates the resonance current magnitude and phase in relation to the frequency, as well as the voltage conversion. As can be seen from (2), the resonance current is directly proportional to the input voltage $V_{\text {In }}$, at a constant operating frequency, which leads to the current drawn from the ac mains is proportional to the ac mains voltage.

This is a very simple way of achieving PFC; no additional components or control are required and in fact it minimizes the components, as the buffer capacitor $C_{B}$ typically is quite large, in order to buffer energy for $10 \mathrm{~ms}(100 \mathrm{~Hz})$. The drawback of doing it this way is that the converted power is modulated by $100 \mathrm{~Hz}$ of the rectified ac mains; hence, the output power will also have this modulation. This $100 \mathrm{~Hz}$ output power modulation is acceptable for this LED application, but for other dc output applications this PFC method might not be applicable. Furthermore, this PFC method has no line and load regulation, resulting in output power variations in connection to ac mains voltage variations. This is again acceptable for this application, but line and load regulation can be achieved and implemented in the control to some extent, by modulating the operation point.



Fig. 5. Magnitude and phase plot of the resonance current $I_{L}$ (2), at a $152 V_{\mathrm{rms}}$ ac input voltage $V_{\text {In }}$ (first harmonic of the half-bridge applied $V_{\text {In }}$ ), as well as a magnitude plot of the voltage conversion. It can be clearly seen that the resonance current phase lag increases as the frequency increases above the resonance frequency, as well as the resonance current and voltage conversion magnitude decrease.

\section{Proposed Forward CONDUCTION Mode CONTROL METHOD}

As described in the previous section, a precise and controlled excitation frequency is crucial, in order to achieve a sustained ZVS operation of the half-bridge switches, but also to ensure a constant operation point. The resonance frequency of the PT varies somewhat with temperature and aging, which also should be tracked and compensated.

The proposed control method accommodates these challenges and as the name implies, the control method relies on a detection of the forward conduction period of half-bridge switches, essentially measuring the periods $t_{2}-t_{3}$ and $t_{5}-t_{6}$ (see Fig. 4). Besides having the advantage of sustaining an optimal operation frequency, the FCM control is also very simple and hence of low cost, as well as it is purely primary based, not needing signals to cross the primary secondary isolation barrier.

The resonance current $I_{L}$ (2) has a phase lag in relation to the input voltage $V_{\text {In }}$, due to the operation above the resonance frequency, in order to achieve the ZVS operation. This phase lag is illustrated in Fig. 5 and is reflected in the forward conduction period, as the switches forward conduction is getting limited at increasing phase lag and this can be used as a feedback signal. At a specific phase lag, hence a specific forward conduction period, the inductivity and resonating energy are maximized and also the ZVS capability.

Fig. 6 illustrates a functional block diagram of the proposed FCM control method. The essential parts are the sense resistor $R_{S}$ and the comparator, which detects the forward conduction period of the low-side switch. Only a low-side current measurement is performed, since this is very simple with a sensing resistor, and using both low and high-side sensing only increases sensitivity, at the expense of circuit complexity. The comparator produces a square-wave signal $V_{\mathrm{SQ}}$ from the current measurement $V_{S}$, containing the forward conduction period information, and in this configuration the signal is inverted, assuming a high 


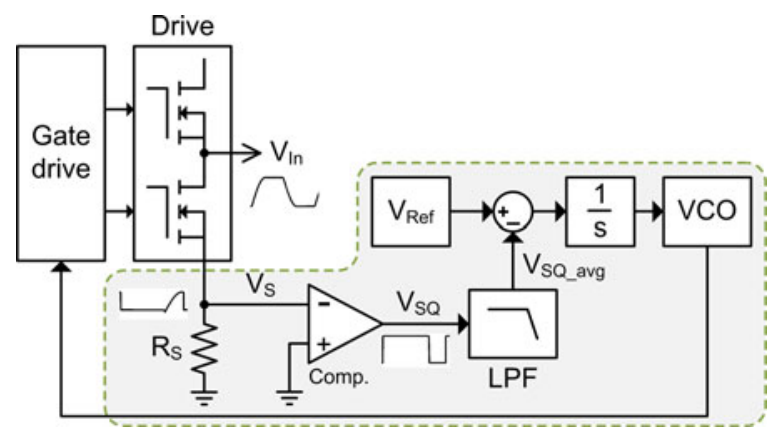

Fig. 6. Block diagram of the FCM control scheme, composing a forward conduction detector (Comp.), an averaging low-pass filter, an error signal generating subtracter, an integrator, and a VCO.

output when the sensing signal $V_{S}$ is zero. This signal is passed through an averaging low-pass filter, where the average signal value is proportional to the forward conduction period (3)

$$
V_{\mathrm{SQ}_{-} \text {avg }}=V_{C C} \cdot \frac{T-T_{\mathrm{FW}}}{T}=V_{C C}\left(1-D_{\mathrm{FW}}\right) \text {. }
$$

The average signal is compared with a reference and the error signal is passed to an integrator that controls a voltage controlled oscillator (VCO). The VCO drives the gate drive, which closes the loop around the half-bridge.

The FCM control operation is illustrated in Fig. 7, at different operation frequencies. It can be seen how the forward conduction period increases, as the frequency is decreased toward the resonance frequency, as well as the resonance current $I_{L}$ increases and the average $V_{\mathrm{SQ}}$ signal decreases. When the frequency is increased away from the resonance frequency, the resonance current $I_{L}$ decreases, the forward conduction period decreases, and the average $V_{\mathrm{SQ}}$ signal increases. The two operating points at 117.7 and $118.6 \mathrm{kHz}$ [see Fig. 7(b) and (c)] are located close to the boundary of ZVS operation and in between these boundaries the ZVS operation is sustained, which can also be observed on the switching flanks of the input signal $V_{\mathrm{In}}$. Beyond these boundaries, ZVS operation is not possible and this is also clear at 115.3 and $121.8 \mathrm{kHz}$ [see Fig. 7(a) and (d)], where hard switching of the input signal $V_{\text {In }}$ is observed. But most importantly the forward conduction period and the average signal $V_{\mathrm{SQ} \text { _avg }}$ are modulated continuously over the frequency range, making it a very applicable feedback signal.

As the point of maximal soft-switching capability and optimal operation is located at a specific resonance current phase lag of approximately $56^{\circ}$ [3], [6], [7], [14]-[16], [20], this point of operation is also linked to a specific forward conduction duty cycle of approximately $26 \%$.

The reference signal should be selected to match the average signal $V_{\mathrm{SQ}_{\text {_avg }}}(3)$ at this forward conduction duty cycle and with a local supply voltage $V_{C C}$ of $15 \mathrm{~V}$, a $11.1 \mathrm{~V}$ reference signal is selected

$$
V_{\mathrm{Ref}}=V_{\mathrm{SQ}_{\text {_avg }}}=V_{C C}\left(1-D_{\mathrm{FW}}\right)=15 \mathrm{~V}(1-0.26)=11.1 \mathrm{~V}
$$

In this manner, the FCM control seeks to maintain a constant forward conduction duty cycle of $26 \%$, and hence a constant resonance current phase lag of $56^{\circ}$, ensuring operation at the

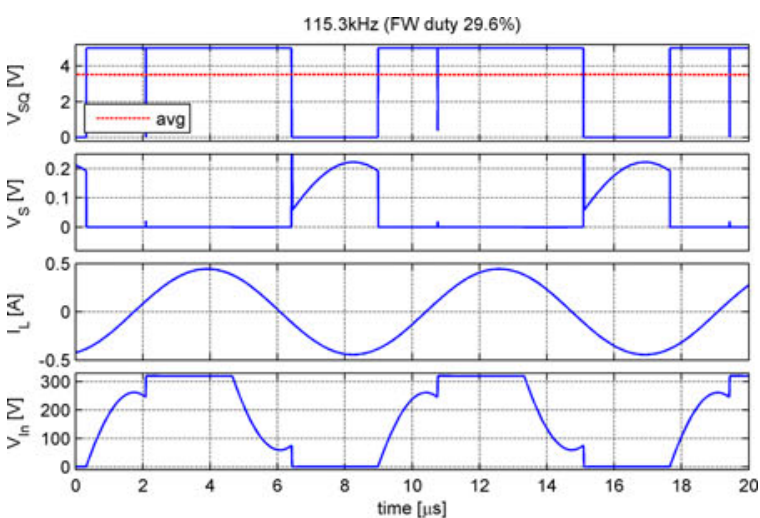

(a)
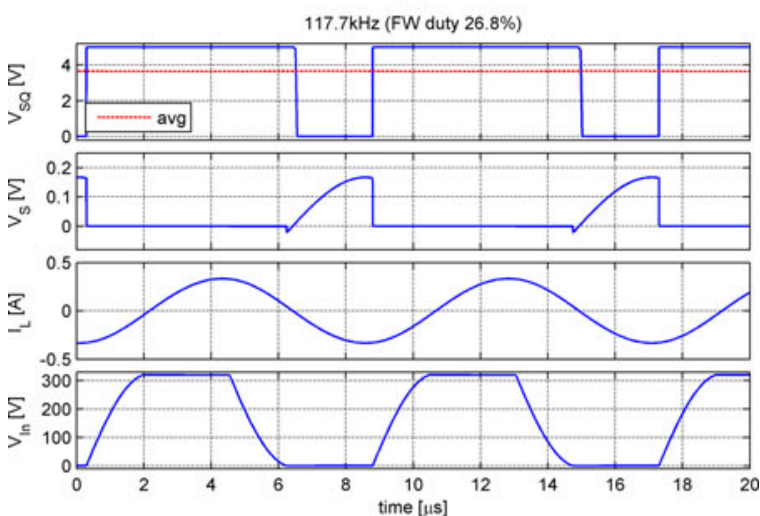

(b)



(c)



(d)

Fig. 7. FCM control operation waveforms, at different operation frequencies and with constant dead time, illustrating the forward conduction period variation. $a$ and $d$ are clearly operated under hard switching, whereas $b$ and $c$ are soft switching. 




Fig. 8. Schematic of prototype PT LED drive, resembling the fundamental blocks of the converter and the FCM control, with the addition of a start-up delay and dead time reference circuit.

optimal point of operation. A clear advantage of this control method is that the feedback signal is not dependent on signal magnitude, such as the resonance current, as the magnitude is modulated by the ac mains for this passive PFC application. Although the zero voltage crossing remains a challenge, the resonance current also reaches zero, making it impossible to detect a forward conduction period. But this is also a challenge for all other control methods and is typically managed by having a very slow control loop. Furthermore, the control method is applicable for variable load and output power, as the optimal point of operation still is linked to the resonance current phase lag and forward conduction period. Although the gain and softswitching capability are load dependent and are changing with load variations.

\section{EXPERIMENTAL RESULTS}

The presented designs were implemented and validated in a developed prototype PT LED drive and the results are presented and discussed in the following section. Pictures of the prototype PT LED drive are shown in Fig. 10, and Fig. 8 shows the circuit schematic of the implementation. The prototype is developed as a PT-based solution of a Fairchild FL6961 Single-stage flyback $8.4 \mathrm{~W}$ LED design proposal. The prototype is designed for 230V $50-\mathrm{Hz}$ ac mains supply and $6.5-\mathrm{W}$ output power; it has an input filter and a full-bridge rectifier. It utilizes a $20-\mathrm{mm}$ radial mode PT and is operated at approximately $117 \mathrm{kHz}$. Furthermore, three seriescoupled OSLON SSL 80 LEDs form the LED load, where the LED load has a nominal voltage of $9.6 \mathrm{~V}$ and a current of $350 \mathrm{~mA}$. In Fig. 9, the operational waveforms of the LED load are shown, where the $100-\mathrm{Hz}$ modulation is obvious.

The converter uses the FAN7387 controller, as it comes with a build-in relaxation oscillator and a gate-drive, with a pro-

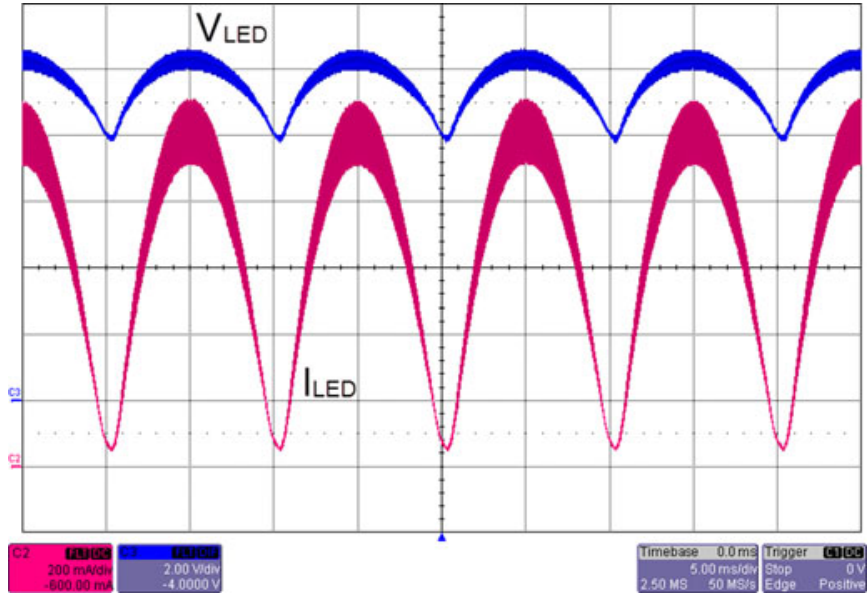

Fig. 9. LED load waveforms, with a $100 \mathrm{~Hz}$ output modulation and an 6.5-W average output power. $V_{\mathrm{LED}}(\mathrm{Ch} 3: 2 \mathrm{~V} / \mathrm{div}), I_{\mathrm{LED}}(\mathrm{Ch} 2: 200 \mathrm{~mA} / \mathrm{div})$, time base $(5 \mathrm{~ms} / \mathrm{div})$.

grammable dead time. The control loop is build around $U 3 A$ and $U 2 B$, where the comparator $U 3 A$ detects the forward conduction period and produces the square-wave signal. The averaging low-pass filter is implemented with two first-order $R C$ low-pass filters, with a corner frequency of $6.6 \mathrm{kHz}$.

The integrator is implemented around the operational amplifier $U 2 B$ and it controls the resistance of the relaxation oscillator, closing the control loop. For this PFC application, the crossover frequency of the integrator is $14.2 \mathrm{~Hz}$, in order to suppress the influence of the zero-voltage crossing.

The relative high dead time required resulted in an abnormal startup of the controller, as the programmable dead-time pin $(S T / \overline{D T})$ also functions as a shutdown input. In order to work 




Fig. 10. Developed prototype LED PT drive, showing the top and bottom sides of the PCB. It utilizes the FAN7387 controller and a 20-mm ZVS optimized radial mode PT, operated at approximately $117 \mathrm{kHz}$. The PCB has a size of $39.5 \times 65 \mathrm{~mm}$.

TABLE II

SIZE COMPARISON OF THE PROTOTYPE PT LED DRIVE AND THE FAIRCHILD F L6961 LED DESIGN PROPOSAL

\begin{tabular}{|l|r|r|l|}
\cline { 2 - 4 } \multicolumn{1}{c|}{} & Prototype & Fairchild & \multicolumn{1}{|c|}{} \\
\hline Output power & 6.5 & 8.4 & W \\
\hline \hline Height & 15.0 & 25.5 & $\mathrm{~mm}$ \\
\hline Width & 39.5 & 38.1 & $\mathrm{~mm}$ \\
\hline Length & 65.0 & 49.5 & $\mathrm{~mm}$ \\
\hline \hline Volume & 38.5 & 48.1 & $\mathrm{~cm}^{3}$ \\
\hline
\end{tabular}

around this, the operational amplifier $U 2 A$ supplies the pin with a low impedance voltage, instead of the traditional way of setting the voltage with a resistor. Furthermore, the comparator $U 3 B$ ensures a certain startup delay, as well as it initializes the integrator through $Q 3$, ensuring a smooth startup and initialization of a high operation frequency.

The utilized radial mode PT occupies a relative large PCB area, but offers a very low profile (4-mm PT thickness) and small overall size of the prototype. The size can be minimized even further by replacing the electrolytic capacitors with ceramic capacitors, as well as the input filter and circuit can be further compressed, by using smaller packaging and a denser layout. Furthermore, the control circuits could be integrated into a controller IC, which both minimizes cost and size. In the design process, the prototype size has not been targeted in particular, but the prototype still offers a reasonable small size, which is compared to the Fairchild F L6961 LED design proposal in Table II.

\section{A. Power Factor Correction}

The ac mains input current of Fig. 12 is both in phase with the input voltage and it somewhat resembles a sinusoidal, although

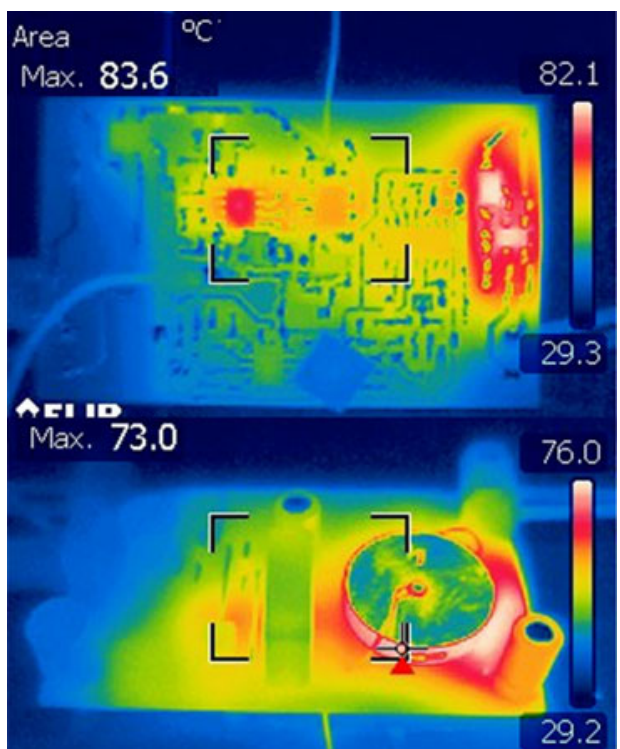

Fig. 11. Thermal IR images of the developed prototype LED PT drive, showing the top and bottom sides of the PCB. The colors indicate the temperature, with light colors being hot and dark colors less hot. The temperature of the PT is misleading, as the PT has a silver electrode on the top, which prevents IR radiation. But a PT temperature of $73{ }^{\circ} \mathrm{C}$ can be seen, as well as the heat from the output rectifier can be observed through the PCB.

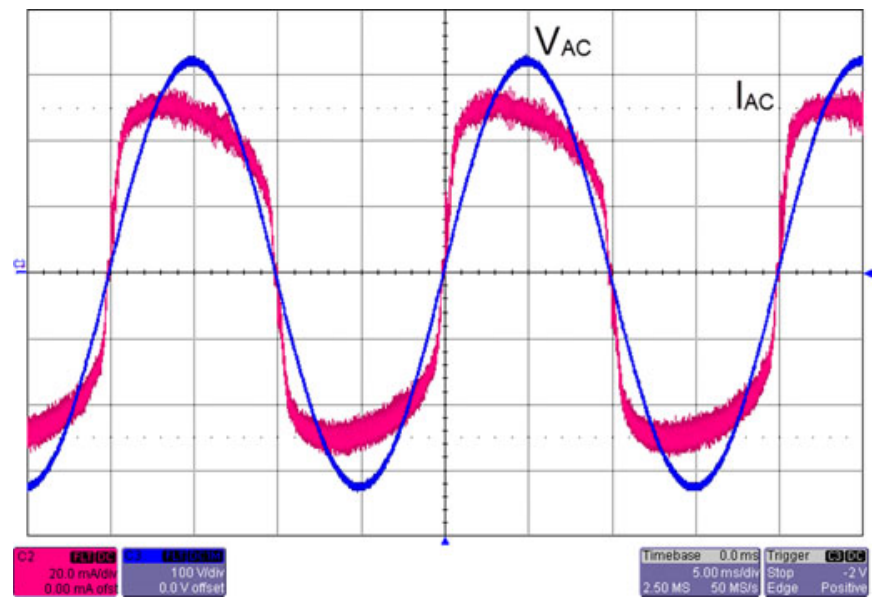

Fig. 12. AC mains input voltage and current, having an input power of $9.5 \mathrm{~W}$ and a power factor of $0.96 . V_{\mathrm{AC}}(\mathrm{Ch} 3: 100 \mathrm{~V} / \mathrm{div}), I_{\mathrm{AC}}(\mathrm{Ch} 2: 20 \mathrm{~mA} / \mathrm{div})$, time base $(5 \mathrm{~ms} / \mathrm{div})$.

it has some distortion. And with a measured power factor of 0.96 , the circuit demonstrates the ability of PFC. In Fig. 13, it is shown how the prototype complies with the EN61000-3-2 standard for current harmonics of Class $\mathrm{C}$ devices and as it can be seen the prototype fails to comply. But it only slightly exceeds the limits for the second and fifth harmonic and it is expected that the harmonics can be improved through further optimization of the circuit and control, which is further discussed in the following section.

\section{B. Forward Conduction Mode}

As described earlier, the FCM control method is based on a forward conduction period detection, which is realized with a 


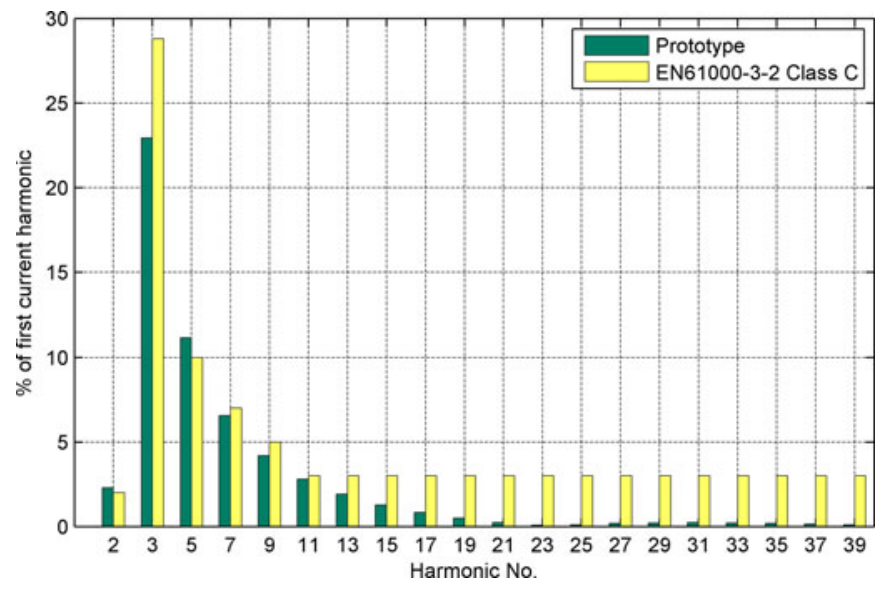

Fig. 13. Comparison of prototype measurements and the EN61000-3-2 standard for current harmonics of Class $\mathrm{C}$ devices.

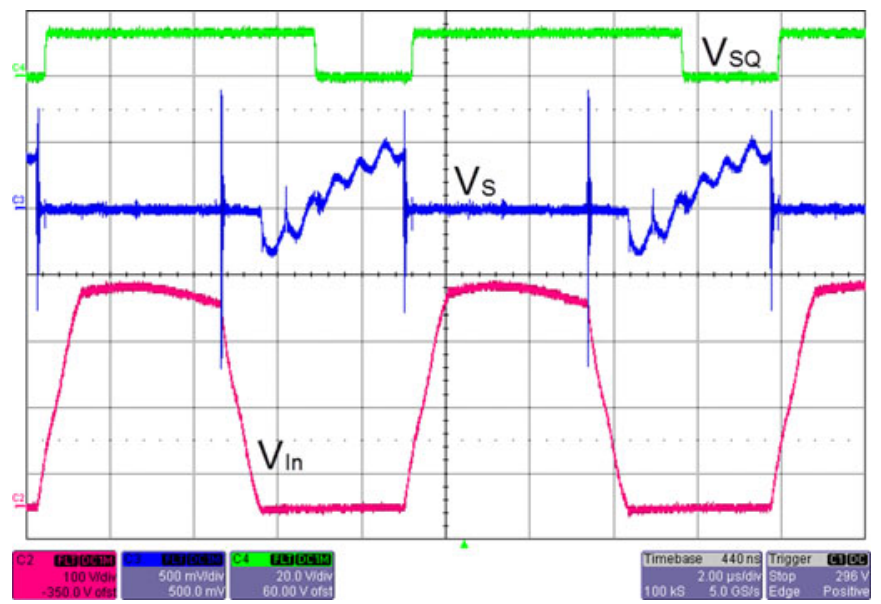

Fig. 14. FCM waveforms, demonstrating the FCM functionality and has a $26.4 \%$ forward duty. $V_{\text {In }}(\mathrm{Ch} 2: 100 \mathrm{~V} / \mathrm{div}), V_{S}(\mathrm{Ch} 3: 500 \mathrm{mV} / \mathrm{div}), V_{\mathrm{SQ}}(\mathrm{Ch} 4$ : $20 \mathrm{~V} / \mathrm{div})$, time base $(2 \mu \mathrm{s} / \mathrm{div})$.

current sense resistor and a comparator. The operational waveforms of the current sense $\left(V_{S}\right)$ and comparator square-wave $\left(V_{\mathrm{SQ}}\right)$ are shown in Fig. 14, near ac mains peak voltage, as well as the PT input voltage $\left(V_{\text {In }}\right)$. The figure demonstrates and validates the functionality of the proposed FCM control method, as well as the ZVS operation of the half-bridge can be observed. On top of the sensed resonance current, a high-frequency signal can be seen. This is one of the higher frequency mode shapes of the PT, which is excited somewhat, but does not affect the functionality of the FCM control. Taking a closer look at the PT input voltage $\left(V_{\text {In }}\right)$, it can be observed that the half-bridge supply voltage has some variance and is not constant as compared to Fig. 4. This is because of the relative low-buffer capacitor $C_{10}$ of $22 \mathrm{nF}$, which allows the resonance current to charge the voltage a little bit and then discharge it, as the resonance tank is charged.

In Fig. 15, the average square-wave feedback signal $\left(V_{\mathrm{SQ}, \text { avg }}\right)$ is shown in relation to the ac mains voltage $\left(V_{\mathrm{AC}}\right)$. As it can be seen, the feedback signal is fairly constant, with the exception



Fig. 15. FCM feedback signal in relation to the ac mains voltage, revealing dropouts in the feedback signal near the zero voltage crossing. $V_{\mathrm{SQ}}$ avg $(\mathrm{Ch} 2$ : $5 \mathrm{~V} / \mathrm{div}), V_{\mathrm{AC}}(\mathrm{Ch} 3: 200 \mathrm{~V} / \mathrm{div})$, time base $(5 \mathrm{~ms} / \mathrm{div})$.

near zero voltage crossing. This is due to the fact that the resonance current also reaches zero, making it impossible to detect a forward conduction period. This issue was expected and in order to have a minimal influence, it is suppressed by having an integrator crossover frequency of only $14.2 \mathrm{~Hz}$.

By taking a closer look at the average feedback signal $\left(V_{\mathrm{SQ}, \text { avg }}\right)$, it can be seen that the "constant" part of the signal in fact has a periodic modulation. Due to the very slow control loop, this is not caused by a variation in operation frequency. This is reflecting a change in operation condition and operation point of the PT, as the LED load does not resemble a resistive load. Therefore, the load impedance seen by the PT also has a $100-\mathrm{Hz}$ modulation, which results in a change in operation condition and resonance frequency. This might suggest to have a faster reacting control loop, which can compensate this change in operation condition, and then take care of the zero-voltage crossing in another way. A solution could be to freeze or pause the integrator near the zero voltage crossing and thereby ignoring the dropout in the feedback. The change in operation point has a negative influence on the PFC and results in a distortion of the input current, which was observed in the previous section. The passive PFC requires a constant operation point, in order to achieve a resonance current proportional to the ac mains voltage. As the operation point changes, the resonance current is in fact not proportional to the ac mains voltage, which degrades the fundamental operational principle of the passive PFC. This results in a little too large resonance current at low voltages and a little too small resonance current at high voltages and explains the somewhat "pressed down" and degraded sinusoidal input current of Fig. 12, which degrades the PFC performance. A faster reacting control loop will improve the PFC performance, as the control will be able to track and compensate these changes under the operation condition. Again, the zero voltage crossing needs to be taken care of in another way. The main advantage of the implemented slow control loop is that it copes with the zero voltage crossing; as well as no additional support circuits are needed. 
TABLE III

LOSS BREAKDOWN OF THE PROTOTYPE LED PT DRIVE

\begin{tabular}{|l|r|r|}
\hline Output power & $6.51 \mathrm{~W}$ & \\
\hline \hline MOSFET drive & $0.26 \mathrm{~W}$ & $2.7 \%$ \\
\hline PT & $1.88 \mathrm{~W}$ & $19.7 \%$ \\
\hline Output rectifier & $0.60 \mathrm{~W}$ & $6.3 \%$ \\
\hline \hline Efficiency & & $68.3 \%$ \\
\hline
\end{tabular}

\section{Efficiency}

The efficiency has not been the main focus point in this research; as well as the utilized PT is not optimized for this particular application, which results in a moderate efficiency. By calculation the efficiency of ac mains input power of Fig. 12 and the output power of Fig. 9, it results in a very moderate efficiency of $68 \%$

$$
\eta=\frac{P_{\mathrm{Out}}}{P_{\mathrm{In}}}=\frac{P_{\mathrm{LED}}}{P_{\mathrm{AC}}}=\frac{6.5[\mathrm{~W}]}{9.5[\mathrm{~W}]}=68 \% .
$$

As the thermal images of Fig. 11 reveal, the PT and the halfbridge output rectifier are the biggest sources of heat. And, it is also within these components that the biggest improvements of the overall efficiency can be obtained. In Table III, a loss breakdown is conducted, where it is obvious that the PT is the most inefficient component, which is a result of the utilized "off-the-shelf" nonapplication optimized PT. The PT is the main efficiency limiting factor for this prototype and by utilizing an application optimized PT, efficiencies above $90 \%$ are achievable. An optimized redial mode PT can be achieved through the design process presented in [19] or [17], where the PT is designed to match the applied load, has a desired gain, which matches the input and output voltages, as well as matching the desired load power, and finally the PT is designed to possess soft-switching capabilities. Other step-down PT structures can also be utilized, such as thickness mode PTs [4], [36]-[38], using the same optimization criteria.

Furthermore, by utilizing an active full-bridge output rectifier, efficiency improvements of $2-5 \%$ points can be expected.

\section{CONCLUSION}

A new FCM control method has been proposed and investigated in this paper. The FCM control method relies on the phase information of the PT resonance current running in the half-bridge switches, which is reflected in the forward conduction period of the switches. The proposed FCM control has been investigated in detail and has demonstrated to operate the PT at its optimal operation frequency, which ensures soft-switching operation and a constant gain.

Furthermore, a PT-based PFC LED drive has been proposed and developed. The devolved prototype is supplied from $230-\mathrm{V}$ $50-\mathrm{Hz}$ ac mains and produces a low voltage $6.5-\mathrm{W}$ output, for three series coupled LEDs. The background and functionality of the utilized inductorless half-bridge topology have been investigated and explained in detail.

A very simple passive PFC method has been proposed, which has demonstrated good PFC capabilities, demonstrating a power factor of 0.96 , and is on the boundary of complying with the EN61000-3-2 standard. The resulting PFC capability has been evaluated and suggestions for improvements have been put forward, in order to improve the PFC capability and comply with the EN61000-3-2 standard.

Moreover, the developed prototype shows good opportunity for minimization and the circuit can be compressed even further. The control circuits can be greatly compressed or even integrated, leaving the PT and the input filter as the only large components.

\section{ACKNOWLEDGMENT}

The authors would like to thank Noliac A/S for supplying prototype PTs, as well as general PT design support. They would also like to thank Fairchild Semiconductors for making this collaboration possible and the Advanced Technology Foundation for their financial support.

\section{REFERENCES}

[1] Z. Ye, F. Greenfeld, and Z. Liang, "A topology study of single-phase offline ac/dc converters for high brightness white LED lighting with power factor pre-regulation and brightness dimmable," in Proc. 34th IEEE Annu. Conf. Ind. Electron.,, Nov. 2008, pp. 1961-1967.

[2] F. Yam and Z. Hassan, "Innovative advances in LED technology," Microelectron. J., vol. 36, no. 2, pp. 129-137, 2005.

[3] K. Meyer, M. Andersen, and F. Jensen, "Parameterized analysis of zero voltage switching in resonant converters for optimal electrode layout of piezoelectric transformers," in Proc. IEEE Power Electron. Special. Conf., Jun. 2008, pp. 2543-2548.

[4] T. Bove, W. Wolny, E. Ringgaard, and K. Breboel, "New type of piezoelectric transformer with very high power density," in Proc. IEEE Int. Symp. Appl. Ferroelectr., 2000, vol. 1, pp. 321-324.

[5] E. Horsley, M. Foster, and D. Stone, "State-of-the-art piezoelectric transformer technology," in Proc. IEEE Eur. Conf. Power Electron. Appl., 2007, pp. $1-10$.

[6] C. Lin, "Design and analysis of piezoelectric transformer converters," Ph.D. dissertation, Virginia Polytechnic Inst. State Univ., Blacksburg, 1997.

[7] R. Lin, "Piezoelectric transformer characterization and application of electronic ballast," Ph.D. dissertation, Virginia Polytechnic Inst. and State Univ., Blacksburg, 2001.

[8] H. Chiu, Y. Lo, J. Chen, S. Cheng, C. Lin, and S. Mou, "A high-efficiency dimmable LED driver for low-power lighting applications," IEEE Trans. Ind. Electron., vol. 57, no. 2, pp. 735-743, Feb. 2010.

[9] H. Chiu, H. Huang, H. Yang, and S. Cheng, "An improved single-stage flyback PFC converter for high-luminance lighting LED lamps," Int. J. Circuit Theor. Appl., vol. 36, no. 2, pp. 205-210, 2008.

[10] W. Yu, J. Lai, H. Ma, and C. Zheng, "High-efficiency dc-dc converter with twin bus for dimmable LED lighting," IEEE Trans. Power Electron., vol. 26, no. 8, pp. 2095-2100, Aug. 2011.

[11] J. Zhang, H. Zeng, and T. Jiang, "A primary-side control scheme for highpower-factor LED driver with TRIAC dimming capability," IEEE Trans. Power Electron., vol. 27, no. 11, pp. 4619-4629, Nov. 2012.

[12] Y. Hu, L. Huber, and M. Jovanovic, "Single-stage, universal-input AC/DC LED driver with current-controlled variable PFC boost inductor," IEEE Trans. Power Electron., vol. 27, no. 3, pp. 1579-1588, Mar. 2012.

[13] J. Garcia, A. J. Calleja, E. Lópcz rominas, D. Gacio Vaquero, and L. Campa, "Interleaved buck converter for fast PWM dimming of highbrightness LEDs," IEEE Trans. Power Electron., vol. 26, no. 9, pp. 2627 2636, Sep. 2011.

[14] M. Rødgaard, T. Andersen, and M. Andersen, "Empiric analysis of zero voltage switching in piezoelectric transformer-based resonant converters," in Proc. Int. conf.power electronics, machines, and drives, 2012, pp. 1-6.

[15] E. Horsley, N. N.-Quang, M. Foster, and D. Stone, "Achieving ZVS in inductor-less half-bridge piezoelectric transformer based resonant converters," in Proc. IEEE Int. Conf. Power Electron. Drive Syst., Nov. 2009, pp. 446-451. 
[16] E. Horsley, A. Carazo, N. N.-Quang, M. Foster, and D. Stone, "Analysis of inductorless zero-voltage-switching piezoelectric transformer-based converters," IEEE Trans. Power Electron., vol. 27, no. 5, pp. 2471-2483, May 2012.

[17] E. Baker, W. Huang, D. Chen, and F. Lee, "Radial mode piezoelectric transformer design for fluorescent lamp ballast applications," IEEE Trans. Power Electron., vol. 20, no. 5, pp. 1213-1220, Sep. 2005.

[18] D. Nielsen, M. Andersen, and K. Meyer, "Preliminary investigations of piezoelectric based LED luminary," in proc. 14th IEEE Eur. Conf. Power Electron. Appl., Sep. 2011, pp. 1-9.

[19] K. Meyer and M. Andersen, "One-shot design of radial mode piezoelectric transformer for magneticless power conversion," in Proc. 26. Аnпи. IEEE Appl. Power Electron. Conf. Expo., 2011, pp. 498-504.

[20] K. S. Meyer, "Modeling of piezoelectric transformers and generic circuit analysis for miniaturization of piezoelectric power converters," Master's thesis, Oct. 2008.

[21] S. Bronshtein, A. Abramovitz, A. Bronshtein, and I. Katz, "A method for parameter extraction of piezoelectric transformers," IEEE Trans. Power Electron., vol. 26, no. 11, pp. 3395-3401, Nov. 2011.

[22] Y. Yuanmao, K. Cheng, and K. Ding, "A novel method for connecting multiple piezoelectric transformer converters and its circuit application," IEEE Trans. Power Electron., vol. 27, no. 4, pp. 1926-1935, Apr. 2012.

[23] S. B.-Yaakov, S. Lineykin, "Maximum power tracking of piezoelectric transformer HV converters under load variations," IEEE Trans. Power Electron., vol. 21, no. 1, pp. 73-78, Jan. 2006.

[24] C. Lin, Y. Chen, J. Chen, and F. Wen, "The elimination of the temperature effect on a piezoelectric transformer in a backlight inverter based on the phase-locked loop technique," in Proc. IEEE Int. Conf. Mechatron., Jul. 2005, pp. 828-833.

[25] J. Alonso, C. Ordiz, and M. D. Costa, "A novel control method for piezoelectric-transformer based power supplies assuring zero-voltageswitching operation," IEEE Trans. Ind. Electron., vol. 55, no. 3, pp. 10851089, Mar. 2008

[26] J. Alonso, C. Ordiz, M. D. Costa, J. Ribas, and J. Cardesin, "High-voltage power supply for ozone generation based on piezoelectric transformer," IEEE Trans. Ind. Appl., vol. 45, no. 4, pp. 1513-1523, Jul./Aug. 2009.

[27] S. Nakashima, T. Ninomiya, H. Ogasawara, and H. Kakehashi, "Piezoelectric-transformer inverter with maximum-efficiency tracking and dimming control," in Proc. 17h Annu. IEEE Appl. Power Electron. Conf. Expo., 2002, vol. 2, pp. 918-923.

[28] S. Choi, K. Lee, and B. Cho, "Design of fluorescent lamp ballast with PFC using a power piezoelectric transformer," IEEE Trans. Ind. Electron., vol. 52, no. 6, pp. 1573-1581, Dec. 2005

[29] J. Díaz, F. Nuño, M. Prieto, and J. M.-Ramos, P. V. Saiz, "Closing a second feedback loop in a dc-dc converter based on a piezoelectric transformer," IEEE Trans. Power Electron., vol. 22, no. 6, pp. 2195-2201, Nov. 2007.

[30] J. Zhou, F. Tao, and F. Lee, "Inductor-less charge pump PFC electronic ballast," in Proc. 36th IAS Annu. Ind. Appl. Conf. Meet., Sep./Oct. 2001, vol. 1, pp. 524-529.

[31] J. Qian, F. Lee, and T. Yamauchi, "A single-stage electronic ballast with power factor correction and low crest factor for fluorescent lamps," in Proc. IEEE IAS Annu. Ind. Appl. Conf., Oct. 1997, vol. 3, pp. 2307-2312.

[32] R. Lin and H. Shih, "Piezoelectric transformer based current-source charge-pump power-factor-correction electronic ballast," IEEE Trans. Power Electron., vol. 23, no. 3, pp. 1391-1400, May 2008.

[33] R. Lin, H. Shih, C. Liu, and K. Liu, "A family of piezoelectric transformerbased bridgeless continuous-conduction-mode charge-pump power-factor correction electronic ballasts," IEEE Trans. Ind. Appl., pp. 1-1, 2011.

[34] G. Ivensky, I. Zafrany, and S.-B. Yaakov, "Generic operational characteristics of piezoelectric transformers," IEEE Trans. Power Electron., vol. 17, no. 6, pp. 1049-1057, Nov. 2002

[35] W. Mason, Electromechanical Transducers and Wave Filters. New York: Van Nostrand Reinhold, 1946.

[36] A. Sánchez, M. Sanz, R. Prieto, J. Oliver, P. Alou, and J. Cobos, "Design of piezoelectric transformers for power converters by means of analytical and numerical methods," IEEE Trans. Ind. Electron., vol. 55, no. 1, pp. 79-88, Jan. 2008
37] M. Sanz, A. Sanchez, P. Alou, R. Prieto, J. Cobos, and J. Uceda, "Step by step multilayer piezoelectric transformer design procedure," in Proc. IEEE 35th Annu. Power Electron. Special. Conf., Jun. 2004, vol. 6, pp. 4669 4675

[38] O. Ohnishi, H. Kishie, A. Iwamoto, Y. Sasaki, T. Zaitsu, and T. Inoue, "Piezoelectric ceramic transformer operating in thickness extensional vibration mode for power supply," in Proc. IEEE Ultrason. Symp., Oct. 1992, vol. 1, pp. 483-488.

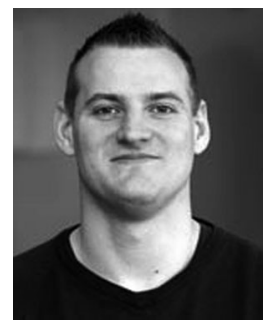

Martin S. Rødgaard received the M.Sc.E.E. degree in power electronics from the Technical University of Denmark, Kongens Lyngby, Denmark, in 2009, where he is currently working toward the Ph.D defense and degree.

$\mathrm{He}$ is currently employed at Noliac A/S, Kvistgaard, Denmark. His research interests include switch-mode power supplies, piezoelectric transformers and piezoelectric transformer-based power converters, satellite power systems, and power factor correction.



Michael Weirich (M'04) received the M.Sc. degree in physics and the Ph.D. degree in solid-state physics from the 'Universität des Saarlandes', Saarbrücken, Germany, in 1991 and 1995, respectively.

Since 1995, he had been with R\&D of signal processing, analog, and power electronics for various companies. At OSRAM GmbH, Munich, Germany, he designed electronic ballast for fluorescent lamps and led a team that developed a $\mu \mathrm{C}$-based family of ballast with advanced features. Since 2003, he has been the Head of Fairchild Semiconductor's European application laboratory, Fürstenfeldbruck, Germany. This laboratory focuses on the design of power electronics and customer support in this area. His current research interests include high-power converters and PSU-based on $\mathrm{SiC}$ devices as well new topologies for LED lighting.

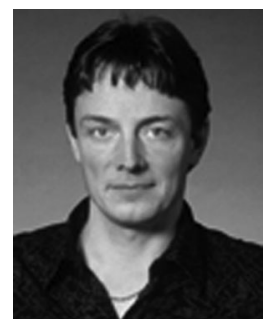

Michael A. E. Andersen (M'88) received the M.Sc.E.E. and Ph.D. degrees in power electronics from the Technical University of Denmark, Kongens Lyngby, Denmark, in 1987 and 1990, respectively.

$\mathrm{He}$ is currently a Professor of Power Electronics at the Technical University of Denmark, where he has been the Deputy Director in the Department of Electrical Engineering since 2009. He is the author or coauthor of more than 100 papers. His research interests include switch-mode power supplies, piezoelectric transformers, power factor correction, and switch-mode audio power amplifiers. 